\title{
Changes in global monsoon precipitation over the past 56 years
}

\author{
Bin Wang ${ }^{1}$ and Qinghua Ding ${ }^{1}$ \\ Received 29 November 2005; revised 15 January 2006; accepted 15 February 2006; published 25 March 2006.
}

[1] Changes in the global monsoon rainfall over land were examined using four sets of rain-gauge precipitation data sets compiled for the period of $1948-2003$ by climate diagnostic groups around the world. Here, we define a global monsoon rain domain according to annual precipitation range, using simple objective criteria; then, we propose metrics for quantifying the intensity of the global monsoon precipitation. The results suggest an overall weakening of the global land monsoon precipitation in the last 56 years, primarily due to weakening of the summer monsoon rainfall in the Northern Hemisphere. However, since 1980, the global land monsoon rainfall has seen no significant trend, which contrasts with the rapid intensification of global warming during the same period. Meanwhile the oceanic monsoon precipitation shows an increasing trend after 1980. The results provide a rigorous test for climate models that will be used in future climatechange assessment. Citation: Wang, B., and Q. Ding (2006), Changes in global monsoon precipitation over the past 56 years, Geophys. Res. Lett., 33, L06711, doi:10.1029/2005GL025347.

\section{Introduction}

[2] Over the past half century, global warming has been underway. The according changes in the monsoon rainfall are of great scientific and societal importance because monsoons define essential features of the Earth's climate, and their rain affects over two-thirds of the world's population. Studying how monsoon rains have changed may provide insight for understanding future changes.

[3] Although many studies have addressed the question of recent monsoon changes, published results have mostly focused on specific regions of the world and have used different measures of monsoon strength [Chase et al., 2003; Kripalani et al., 2003; Jones et al., 2004; Schreck and Semazzi, 2004; Zhai et al., 2005]. The results show considerable uncertainty regarding whether or not global warming has affected the Asian summer monsoon variability. For instance, the observed all-Indian precipitation over the past 131 years does not show global warming controlling the Indian monsoon trend [Kripalani et al., 2003]. On the other hand, Stephenson et al. [2001] have shown that monsoon strength has been decreasing at a rate of $1 \%$ to $3 \%$ per decade; their research was based on National Center for Environmental Prediction/National Center for Atmospheric Research (NCEP/NCAR) reanalysis data and the different monsoon wind shear indices. Chase et al. [2003] found that the monsoonal overturning circulations over the Australia-

\footnotetext{
${ }^{1}$ Department of Meteorology and International Pacific Research Center, School of Ocean and Earth Science and Technology, University of Hawai'i at Manoa, Honolulu, Hawaii, USA.
}

Copyright 2006 by the American Geophysical Union. 0094-8276/06/2005GL025347\$05.00
Maritime continent and African regions have diminished since 1950, but they detected no significant changes since 1979 in the monsoon circulation accompanying the strongest reported surface warming.

[4] Variability of a regional monsoon often results from interaction with circulations from other regions; even within the same global warming environment, each regional monsoon may behave differently because of variations in land surfaces, in conditions of the adjacent oceans, and in teleconnection with El Niño/South Oscillation (ENSO). Examination of monsoon variability from a global perspective is desirable, considering the physical principle of conservation of mass, moisture, and energy as it applies to the global atmosphere and its exchange of energy with the underlying surfaces.

[5] Trenberth et al. [2000] defined the global monsoon system as a global-scale persistent overturning of the atmosphere, throughout the tropics, that varies according to the time of year. Basic theory has shown that over the tropics, there is ascent in the region of heating, with adiabatic cooling balancing the diabatic heating. Thus, the global atmospheric overturning is intimately associated with seasonal variation of monsoon precipitation, which plays a key role in driving monsoon circulations through latent heat release.

[6] Changes in the global monsoon precipitation as a whole, however, have not been investigated. The present study aims to address the following questions: How is the strength of the global monsoon precipitation best measured? What are the major characteristics describing the spatial distribution of observed trends in global monsoon precipitation? And to what extent is long-term variability in the global monsoon potentially attributed to global warming?

\section{Data Sets}

[7] Four sets of monthly rain-gauge precipitation data for global land surfaces on a 0.5 degree latitude/longitude grid compiled by climate diagnostic groups around the world were used: (1) the data set compiled by Delaware University (Delaware) for the period of 1950-1999, (2) the Precipitation REConstruction data over Land (PREC/L) compiled for the period of 1948-2003 by the Climate Prediction Center at the National Center for Environmental Prediction, (3) the data set developed in Global Precipitation Climatology Centre within the project Variability Analysis of Surface Climate Observations (VASCO) for the period of 19512000, and (4) the data set constructed by the Climatic Research Unit (CRU) for the period of 1948-2002. These four data sets share the same database as their sources, the Global Historical Climatology Network v2, which is a comprehensive, global-surface baseline climate data set (with about 17,000 stations) designed to monitor and detect climate change. However, each data set has added its own 

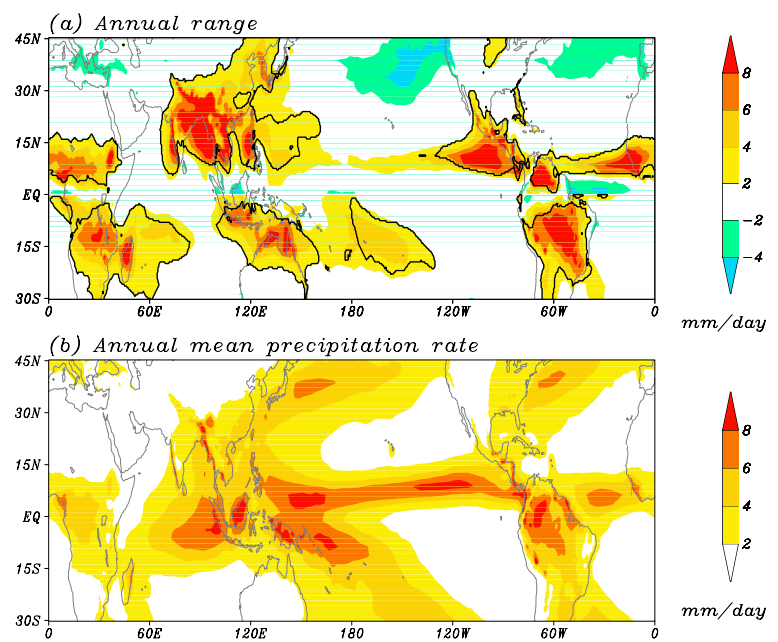

Figure 1. (a) The climatological mean for the annual range of precipitation, defined by the local summer mean precipitation rate (June to August in the Northern Hemisphere, and December to February in the Southern Hemisphere) minus the local winter mean precipitation rate. The bold lines delineate the global monsoon domain. (b) The long-term mean for total annual precipitation. The data used are a blended GPCP data (1979-2003) and the means of the four precipitation data sets (described in the text) for the period of $1948-2003$.

independent information from other sources to enhance its spatial-temporal coverage: Legates and Willmott's station records were added to the Delaware, the Climate Anomaly Monitoring System was included in the PREC/L, the historical database of the UN's Food and Agriculture Organization was combined with the VASCO, and the Hulme [Hulme et al., 1998] precipitation database was added to the CRU. Discrepancies among the four data sets are mainly found over the Tibetan Plateau, the Maritime Continent and South America.

[8] To reduce the uncertainties arising from differences in data sources and interpolation algorithms, an ensemble (arithmetic) mean of the four data sets was calculated over the global land areas for the period of 1948-2003. In addition, Global Precipitation Climatology Project (GPCP) data for the period of 1979-2003 were used to investigate global monsoon trends over ocean areas during the last 25 years [Huffman et al., 1997].

\section{Definition of Monsoon Domain and the Metrics for the Global Monsoon Intensity}

[9] The monsoon climate is characterized by a rainy summer and a dry winter and by annual reversal of prevailing surface winds. Precipitation is the most fundamental variable for defining the monsoon climate and the most influential variable on human existence. One of the simplest measures of monsoon precipitation intensity is the local summer-minus-winter precipitation, defined as the annual range (AR). Here, summer means June-July-August (JJA) in the Northern Hemisphere (NH) and December-JanuaryFebruary (DJF) in the Southern Hemisphere (SH).

[10] Figure 1a shows the global distribution of AR of the climatological precipitation. The global monsoon precipita- tion domain is defined by the regions in which the AR exceeds $180 \mathrm{~mm}$ and the local summer monsoon precipitation exceeds $35 \%$ of annual rainfall. The first criterion distinguishes monsoon from semi-arid and Mediterranean (Trade wind) climate and the second threshold warrants a concentrated summer rainy season and distinguishes monsoon from perennial rain regime. This simplistic definition is in an excellent agreement with the monsoon domains that have been previously defined based upon more complex multiple criteria [Wang and Ho, 2002]. The major monsoon rainy regions tend to reside on each side of the equatorial perennial rainfall regions (Figure 1a). The global monsoon rainfall differs from and is complementary to that of the global mean precipitation, which tends to be maximized at the equator and is generally more equatorially symmetric (Figure1b).

[11] To measure the monsoon precipitation intensity, we used three complementary methods. Our first method measured global mean intensity. Since the monsoon annual range is dominated by local summer precipitation, we used the NH-averaged JJA "monsoon precipitation" (i.e., the precipitation falling in the $\mathrm{NH}$ monsoon domain) and the $\mathrm{SH}$-averaged DJF monsoon precipitation to measure the strength of the $\mathrm{NH}$ and $\mathrm{SH}$ summer monsoon rainfalls, denoted by NHMI and SHMI, respectively. The sum of NHMI and SHMI in the following season was used to quantify the strength of the global mean monsoon strength; we have termed this the Global Monsoon Index (GMI). Our second approach was designed to reveal the coherent pattern of the change in global monsoon intensity (AR). The annual range (AR) varies from year to year. Therefore, each year's

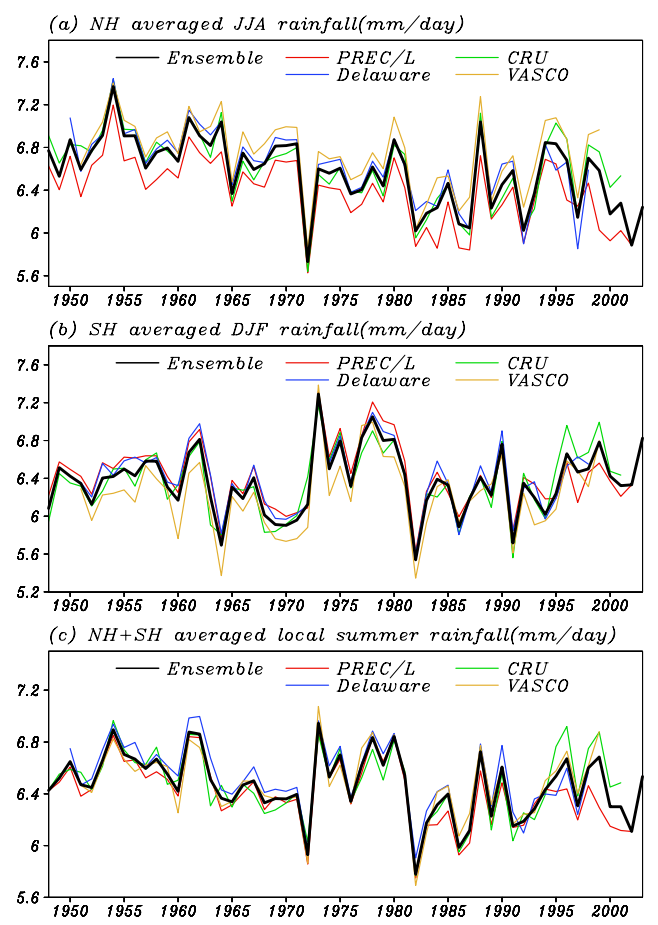

Figure 2. Time series of (a) the Northern Hemisphereaveraged June-July-August precipitation, (b) the Southern Hemisphere-averaged December-January-February precipitation, and (c) the global monsoon index (GMI), or the sum of Figures 1a and 1b. 
(a)

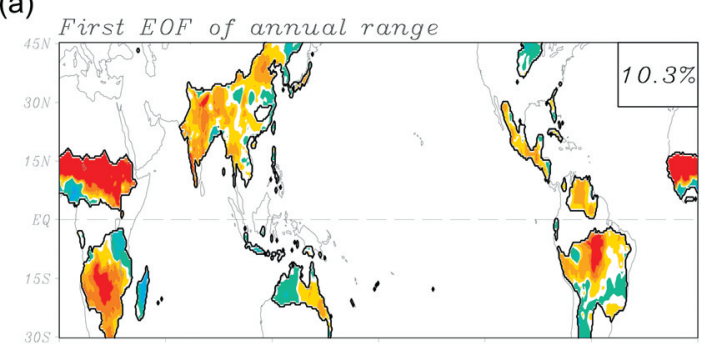

(b)

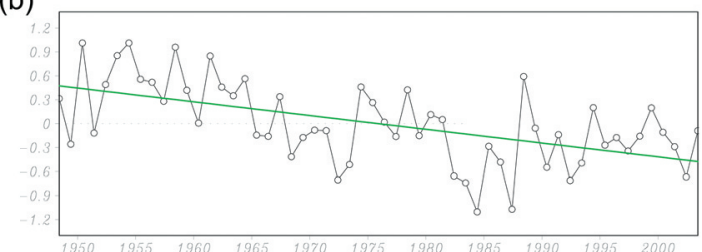

Figure 3. (a) The spatial pattern of the leading Empirical Orthogonal Function (EOF) mode of the normalized annual range anomalies over the global continental monsoon regions; (b) the corresponding principle component or annual range index (ARI). The bold contour indicates the boundaries of the monsoon domain.

AR was defined as the local summer precipitation minus the preceding local winter precipitation. Using this definition, the annual range varies by location. The leading Empirical Orthogonal Function (EOF) pattern of yearly AR was used to describe the primary spatial variability of AR, while the corresponding time coefficient was used to describe temporal behavior; this we have termed the Annual Range Index (ARI). Our third method tested the statistical significance of the AR trend for each grid point within the monsoon domain. The grid points that showed significant trends yielded a spatial pattern that can be compared to the results derived from the leading EOF pattern.

\section{Results}

[12] Although the defined monsoon domain includes both land and ocean, we first confined our analysis to land monsoon regions because the land-based rain gauge observations are reliable and cover a longer period (56 years). Figure 2 shows the time series of the GMI, NHMI, and SHMI; the three time series show the three indices derived from all four data sets, along with their ensemble mean data. The discrepancies among the four data sets are generally moderate, and their trends are consistent. The ensemble mean time series indicates a decreasing trend in the global monsoon index across the entire 56 years, and particularly before 1980. The nonparametric Mann-Kendall rank statistics [Kendall, 1955] show that both the GMI and NHMI are significant at the $95 \%$ confidence level. The conclusions derived from all four individual data sets are very consistent and confirm the above conclusions. The SHMI, however, shows no significant trend.

[13] Figure 3a shows the coherent spatial pattern of the leading EOF mode of the global land monsoon precipitation $\mathrm{AR}$, which is obtained by analysis of the correlation matrix based on the four-member ensemble mean precipitation data set. The corresponding ARI shows a decreasing tendency for the entire period examined (Figure 3b). Based on Mann-
Kendall rank statistics, the decreasing trend of ARI is significantly different from zero at the $99 \%$ confidence level. The same conclusion applies to the results derived from each individual data set. The majority of land monsoon regions show a coherent decreasing trend, with the largest amplitude over Africa. The ARI shows significant interannual to interdecadal variability, but the interannual variation does not significantly relate to ENSO, which is different from the global mean precipitation.

[14] Figure 4 presents the statistical significance of the $\mathrm{AR}$ trend at each grid point within the land monsoon domain. Two methods were used to test the significance of linear trends: the trend-to-noise ratio, shown in Figure 4a, and Mann-Kendall rank statistics, illustrated in Figure 4b. The significant spatial patterns detected by the two distinct methods are consistent; they also corroborate the results of the EOF analysis. A strong decreasing trend in monsoon rain intensity was found for northern Africa, the Bangladesh/northern India/eastern Tibetan Plateau, northern China, and central South America; increasing monsoon strength was seen over northwest Australia.

[15] Consistent with the finding of Chase et al. [2003], the declining trend of both the GMI and the ARI has been leveling off since 1980 (Figures 2 and 3), even though the global mean temperature has experienced the most rapid increase during this period. Figure 2 indicates that the $\mathrm{SH}$ monsoon has no significant trend. In fact, after the $1982 \mathrm{El}$ Niño, there appears to be a slight increasing tendency, which may partially explain the slowdown of the decreasing trend in global monsoon precipitation over land.

[16] The GPCP data set provides global precipitation measurements over the last 25 years, charted on a 2.5 by 2.5 degree grid. The climatological, globally averaged precipitation rate is $2.61 \mathrm{~mm} /$ day, with a tiny yearly standard deviation of $0.03 \mathrm{~mm} / \mathrm{day}$; no trend was seen for the total global precipitation [Allen and Ingram, 2002].
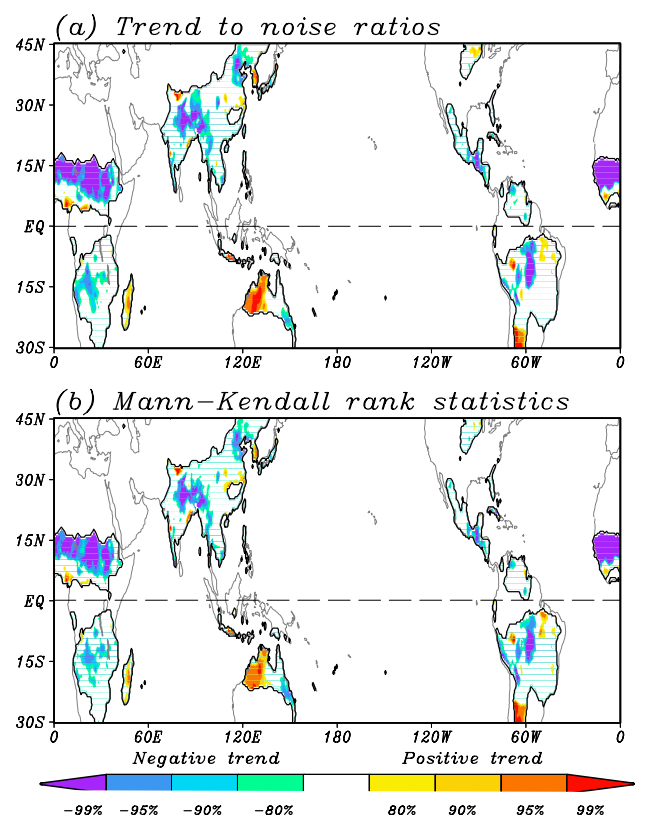

Figure 4. Statistical significance of the linear trends in summer monsoon precipitation at each grid point. (a) Trendto-noise ratio and (b) Mann-Kendall rank statistics. 


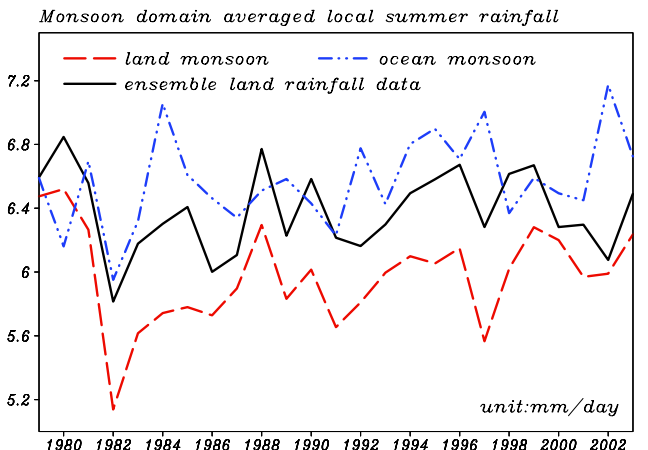

Figure 5. The GPCP global monsoon index (GMI) over land area and ocean area, respectively. Also shown is the GMI over land regions, derived from the ensemble landbased rain-gauge data.

What about global monsoon precipitation, particularly over the oceanic monsoon region? To answer this question, we divided the global monsoon domain, shown in Figure 1, into land and ocean portions. Figure 5 shows that no significant trend was detected for the global land monsoon region, which is consistent with the conclusion derived from analysis of ensemble mean land-based rain gauge precipitation; however, there is an increasing trend over the oceanic summer monsoon region, significant at the $95 \%$ confidence level.

\section{Discussion}

[17] The tropical atmospheric moisture content, latent heating, and overall hydrological cycle have been hypothesized to enhance with increasing tropospheric temperature [e.g., Intergovernmental Panel on Climate Change, 2001]. The numerical simulations with increasing greenhouse gas content generally show increased intensity of the Asian summer monsoonal circulations [e.g., Meehl and Washington, 1993; Hulme et al., 1998]. The inclusion of aerosols, however, seems to suppress the simulated increasing trends in southeast Asia seen in many general circulation model simulations [e.g., Mitchell and Johns, 1997], but not in all [e.g., Roeckner et al., 1999]. The present results provide a rigorous test for climate models that will be used in future climate change assessments.

[18] Examination of monsoon rainfall for the period 1930-1970 suggests an increasing trend over Bangladesh [Kripalani et al., 1996] and over North China [Kripalani and Kulkarni, 2001]. Thus, the decreasing trend in North China and Bangladesh (Figure 4) derived here from data representing a limited length of time should be cautiously considered. It is conceivable that the trend observed over the last 56 years reflects a transition from a strong phase to a weak phase in the multi-decadal variability. Previous studies have suggested that a rapid change occurred in atmospheric circulation and ENSO in the mid-1970s [e.g., Trenberth and Hurrell, 1994]. The results shown here (Figures 2a and 3b) suggest that changes in the $\mathrm{NH}$ monsoon strength reflects this "regime shift," which may be a portion of the Inter- decadal Pacific Oscillation, a period of 50 to 70 years [Folland et al., 1999], or caused by changes in tropical/ sub-tropical land cover and high latitude snow cover [Meehl, 1994; Chase et al., 1996]. There is much we have yet to learn about the causes of observed trends in the global monsoon.

\section{References}

Allen, M. R., and W. J. Ingram (2002), Constraints on future changes in climate and the hydrologic cycle, Nature, 419, 224-232.

Chase, T. N., R. A. Pielke, T. G. F. Kittel, R. Nemani, and S. W. Running (1996), Sensitivity of a general circulation model to global changes in leaf area index, J. Geophys. Res., 101, 7393-7408.

Chase, T. N., J. A. Knaff, R. A. Pielke Sr., and E. Kalnay (2003), Changes in global monsoon circulations since 1950, Nat. Hazards, 29, 229-254.

Folland, C. K., D. E. Parker, A. W. Colman, and R. Washington (1999), Large scale modes of ocean surface temperature since the late nineteenth century, in Beyond El Niño: Decadal and Interdecadal Climate Variability, edited by A. Navarra, pp. 73-102, Springer, New York.

Huffman, G. J., et al. (1997), The Global Precipitation Climatology Project (GPCP) combined precipitation dataset, Bull. Am. Meteorol. Soc., 78, $5-$ 20 .

Hulme, M., T. J. Osborn, and T. C. Johns (1998), Precipitation sensitivity to global warming: Comparison of observations with HadCM2 simulations, Geophys. Res. Lett., 25, 3379-3382.

Intergovernmental Panel on Climate Change (2001), Climate Change 2001. The Scientific Basis: Contribution of Working Group I to the Third Assessment Report of the Intergovernmental Panel on Climate Change, edited by J. T. Houghton et al., 881 pp., Cambridge Univ. Press, New York

Jones, D., D. Collins, N. Nicholls, J. Phan, and P. Della-Marta (2004), A new tool for tracking Australia's climate variability and change, Bull. Aust. Meteorol. Oceanogr. Soc., 17, 65-69.

Kendall, M. G. (1955), Rank Correlation Methods, 2nd ed., 196 pp., Oxford Univ. Press, New York.

Kripalani, R. H., and A. Kulkarni (2001), Monsoon rainfall variations and teleconnections over south and east Asia, Int. J. Climatol., 21, 603-616.

Kripalani, R. H., S. Inamdar, and N. A. Sontakke (1996), Rainfall variability over Bangladesh and Nepal: Comparison and connections with features over India, Int. J. Climatol., 16, 689-703.

Kripalani, R. H., A. Kulkarni, S. S. Sabade, and M. L. Khandekar (2003), Indian monsoon variability in a global warming scenario, Nat. Hazards, 29, $189-206$

Meehl, G. A. (1994), Influence of the land surface in the Asian summer monsoon: External conditions versus internal feedbacks, J. Clim., 7, $1033-1049$

Meehl, G. A., and W. M. Washington (1993), South Asian summer monsoon variability in a model with doubled atmospheric carbon dioxide concentration, Science, 260, 1101-1104.

Mitchell, J. F. B., and T. C. Johns (1997), On modification of global warming by sulfate aerosols, J. Clim., 10, 245-267.

Roeckner, E., L. Bengttson, J. Feichter, J. Lelieveld, and H. Rodhe (1999), Transient climate change simulations with a coupled atmosphere-ocean GCM including the tropospheric sulfur cycle, J. Clim., 12, 3004-3032.

Schreck, C. J., III, and F. H. M. Semazzi (2004), Variability of the recent climate of eastern Africa, Int. J. Climatol., 24, 681-701.

Stephenson, D. B., H. Douville, and K. Rupa Kumar (2001), Searching for a fingerprint of global warming in the Asian summer monsoon, Mausam, $52,213-220$.

Trenberth, K. E., and J. W. Hurrell (1994), Decadal atmosphere-ocean variations in the Pacific, Clim. Dyn., 9, 303-319.

Trenberth, K. E., D. P. Stepaniak, and J. M. Caron (2000), The global monsoon as seen through the divergent atmospheric circulation, J. Clim., 13, 3969-3993.

Wang, B., and L. Ho (2002), Rainy season of the Asian-Pacific summer monsoon, J. Clim., 15, 386-398.

Zhai, P. M., X. B. Zhang, H. Wan, and X. H. Pan (2005), Trends in total precipitation and frequency of daily precipitation extremes over China, J. Clim., 18, 1096-1108.

Q. Ding and B. Wang, Department of Meteorology, University of Hawai' at Manoa, 1680 East-West Road, POST 401, Honolulu, HI 96822-2219, USA. (wangbin@hawaii.edu) 